\title{
Common Site of Urinary Calculi in Kidney, Ureter and Urinary Bladder Region: Jos Experience
}

\author{
${ }^{1}$ Danjem SM, ${ }^{1}$ Salaam AJ, ${ }^{2}$ Kolade-Yunusa HO, ${ }^{3}$ Shuaibu SI
}

${ }^{1}$ Radiology Department, College of Health Sciences, University of Jos PMB 2084, Plateau State, Nigeria.

${ }^{2}$ Radiology Department, University of Abuja, Gwagwalada, Abuja FCT

${ }^{3}$ Urology Unit, Surgery Department, College of Health Sciences, University of Jos PMB 2084, Plateau State, Nigeria.

Correspondence: Danjem Samuel Moses,

\begin{abstract}
Objective: To determine the common location of calculus along the urinary tract using CT scan.

Methods: This cross sectional study was conducted using CT from November 2016 to September 2018, in a tertiary hospital in Jos, Nigeria. The CT images acquired from this period were evaluated and 50 patients were positive for urolithiasis. The data was subjected to statistical analysis based on age, gender and calculus location.

Results: Out of the 50 patients with calculi, 34 were males and 16 were females with a male to female ratio of 2.13:1. 137 urinary calculi were documented in which 90 were in males and 47 in the female patients. Highest occurrence of calculi was seen in age group 31-40 years (34.0\%). 112(82\%) were renal stones, $12(9 \%)$ were ureteric stones, $8(6 \%)$ were found in pelvi-ureteric junction (PUJ), $3(2 \%)$ were in the vesico-ureteric junction (VUJ), 2(1\%) were in the urinary bladder and none in the urethra.

Conclusion: Kidney stones are the most common followed by the ureter, the pelvi-ureteric junction, the vesico-ureteric junction and the bladder.
\end{abstract}

Key Words: Common site; urinary calculi, CT scan.

\section{Introduction}

Urolithiasis is the presence of stone (calculus) anywhere in the urinary tract which includes the kidneys, ureters and the urinary bladder ${ }^{1}$. Urolithiasis is the common finding in patients who presents with acute flank pain and or haematuria. The prevalence and incidence of urolithiasis is reported to be increasing across the world involving both industrialized and the developing countries due to changes in social and economic conditions. The problem of stone is more predominant in the productive age groups even though the incidence is said to be increasing across sex, age and race ${ }^{2,3}$.

It has been reported that approximately 1.2 million Americans are affected annually, and it is estimated that up to $14 \%$ of men and $6 \%$ of women will develop stone disease during their lifetime ${ }^{4,5}$. In addition, many patients will be affected by multiple stones throughout their lifetime, with estimated recurrence rates of $50 \%$ within 5-10 years and 75\% within 20 years. In Nigeria, the hospital incidence of 25.75 per 100,000 and 19,1 per 100,000 were documented for the North West and South East regions respectively ${ }^{6,7}$.

Even though the cause of urolithiasis is not known, some researchers attribute the incidence of nephrolithiasis to a dietary protein ${ }^{8}$.

Calculi can be located anywhere along the urinary tract. A study carried out in Nepal documented the commonest location of calculi to be in the kidneys, followed by the ureter, vesico-ureteric junction, pelviureteric junction and the urinary bladder in descending order ${ }^{8}$. Cao et al $^{9}$ reported $20 \%$ of urinary tract stones found in the ureters, with $75 \%$ of these at the lower one third of the ureter. 
Imaging is the only investigating modality to confirm the presence of calculus, to determine its size, location, possibility of it to be passed, complications as well as for follow up. Various imaging modalities are available to diagnose and locate urinary calculi including plain abdominal radiography of the kidney ureter bladder (KUB), ultrasonography (USG), intravenous urography (IVU) and computed tomography (CT) scan. CT scan has become the investigation of choice for detection and characterization of urinary calculi because of its high sensitivity. When intravenous contrast is given i.e computed tomography urography (CTU), function of the kidney is also assessed. It is however expensive and not readily available in all parts of the world. Radiation dose to the patient is also high. USG is good method for detection of kidney and bladder calculi and features of urinary obstruction. However, it has low detection rate for ureteric calculi. IVU requires use of iodinated contrast agent and gives high radiation dose. Plain radiograph KUB is cheaper and readily available investigation for the detection of radiopaque stone in KUB region. However, it is not specific for urinary calculi. Since, CT is very sensitive in detecting urinary calculi, it was employed in our study ${ }^{10}$.

Treatment of urinary calculi depends on the size and location as well as the symptoms and complications arising from the calculus, hence it is necessary to ascertain the exact location of the stone along the urinary tract.

\section{AIMS AND OBJECTIVES}

The aim of this study was to determine the common site of urinary calculi in the kidney, ureter and urinary bladder using CT.

The specific objective was to:

Assess the side commonly affected

\section{Methodology}

The cross-sectional study was conducted from November 2016 to September 2018 at Jos University Teaching Hospital. The study included all patients with acute flank pain who were referred to radiology department for Computed Tomography Urography (CTU) as well as those incidentally detected on abdominal CT scan during the period under study.

Patients were examined using a 4-slice CT scanner Bright Speed GE (General Electric) Medical Systems (USA). CT scans were obtained from the xiphisternum to the upper thigh with the following technique: a collimator of $5 \mathrm{~mm}$, a pitch of 6 , and with $200 \mathrm{mAs}$. Post intravenous (IV) contrast images were also acquired to determine renal function. Images were reconstructed at a thickness of $2.5 \mathrm{~mm}$ with intervals of $1.25 \mathrm{~mm}$. Three-dimensional (3D) reconstructions of the nonenhanced CT images were performed on the console as well as the work station. 3D reconstructions in coronal and sagittal projections were created for accurate location of the calculus.

The unenhanced CT images were reviewed and 50 patients were consecutively selected based on the criterion of positive urinary tract calculi. All the selected cases were classified according to their sites: Kidney, Pelvi-ureteric junction (PUJ), Ureter, Vesico-ureteric junction (VUJ) and urinary bladder as well as the urethra. The data generated were analyzed with outcome measures of age, gender and stone location by Micro-soft Excel version 2007.

\section{Inclusive Criteria}

Adults of age $\geq 18$ years for CTU or for abdominal CT scan who were positive for calculi.

\section{Exclusive Criteria}

1) Patients with a normal CTU findings.

\section{Result}

During the study period, 50 patients were found with calculi in different anatomical site along the urinary tract. Of the 50 patients $34(68 \%)$ were male and $16(32 \%)$ were female, with a male to female ratio of 2.13:1 (Figure 1). The mean age of our study population was 47.5 (range $24-90$ years). Out of the 50 patients with calculi 17 (34\%) and 14(28\%) belong to the age groups 31-40 and 41-50 respectively (Table 1). 


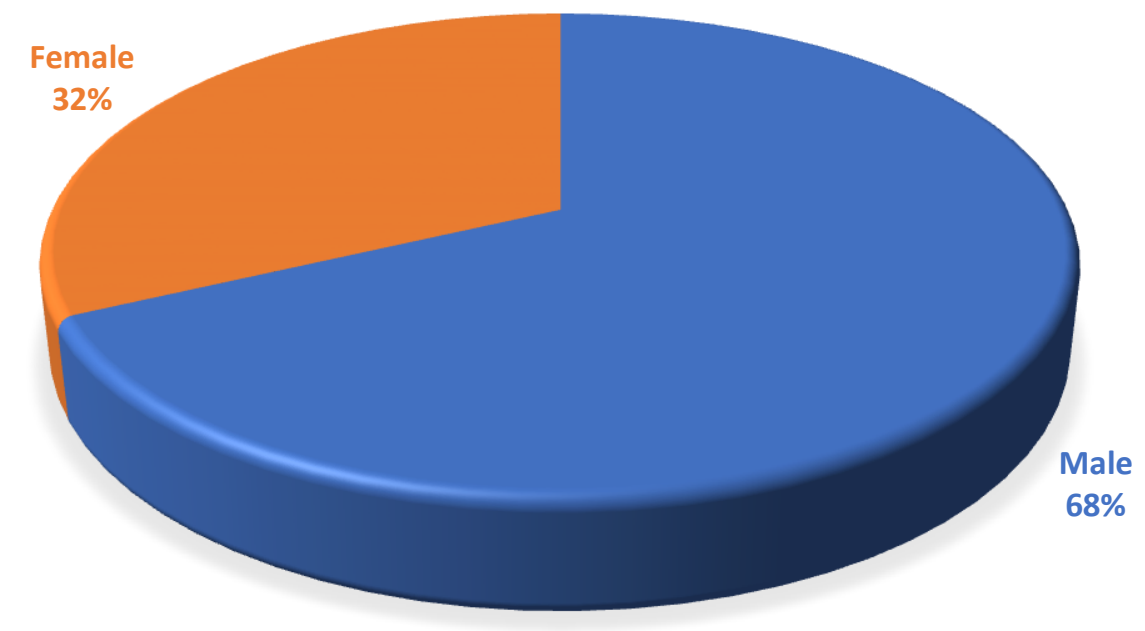

Figure 1: Pie chart showing the sex distribution of the study population.

Table 1: Age and sex distribution of urolithiasis

\begin{tabular}{|c|c|c|c|c|}
\hline Age group & \multicolumn{2}{|c|}{ Gender } & \multicolumn{2}{c|}{ Total } \\
\hline & Male & Female & $\mathrm{N}$ & $\%$ \\
\hline $21-30$ & 2 & 1 & 3 & 6 \\
\hline $31-40$ & 8 & 9 & 17 & 34 \\
\hline $41-50$ & 11 & 3 & 14 & 28 \\
\hline $51-60$ & 6 & 1 & 7 & 14 \\
\hline $61-70$ & 4 & 1 & 5 & 10 \\
\hline $71-80$ & 2 & 0 & 2 & 4 \\
\hline $81-90$ & 1 & 1 & 2 & 4 \\
\hline Total & 34 & 16 & 50 & 100 \\
\hline
\end{tabular}

Total number of urinary calculi was 137 in which 90 were found in male patients and 47 were found in female patients. Analysis of age groups showed a high occurrence of urinary stones among adults between $31-40$ years $(34.0 \%)$. Urolithiasis in males and females was observed highest in the age group 41-50 years $(21.2 \%)$ and age group 31-40 (16.1\%) respectively (Table-2).

Table 2: Showing the age and sex distribution of urolithiasis.

\begin{tabular}{|c|l|l|}
\hline \multicolumn{2}{|l|}{ Gender } & $\begin{array}{l}\text { Total } \\
\text { Number (\%) of } \\
\text { calculi }\end{array}$ \\
\cline { 1 - 2 } $\begin{array}{l}\text { Male } \\
\text { Number (\%) } \\
\text { of calculi }\end{array}$ & $\begin{array}{l}\text { Female } \\
\text { Number (\%) } \\
\text { of calculi }\end{array}$ & $10(7.3)$ \\
\hline $8(5.8)$ & $2(1.5)$ & \\
\hline
\end{tabular}




\begin{tabular}{|l|l|l|}
\hline $28(20.4)$ & $22(16.1)$ & $50(36.5)$ \\
\hline $29(21.2)$ & $6(4.4)$ & $35(25.5)$ \\
\hline $9(6.6)$ & $1(0.7)$ & $10(7.3)$ \\
\hline $12(8.8)$ & $15(10.9)$ & $27(19.7)$ \\
\hline $3(2.2)$ & 0 & $3(2.2)$ \\
\hline
\end{tabular}

In both males and female patients, $112(82 \%)$ calculi were located in the kidney, followed by the ureter with $12(9 \%)$, PUJ with $8(6 \%)$, VUJ with $3(2 \%)$ with the least stones $2(1 \%)$ seen in the Urinary bladder. No stone was located in the urethra (Figure 2).

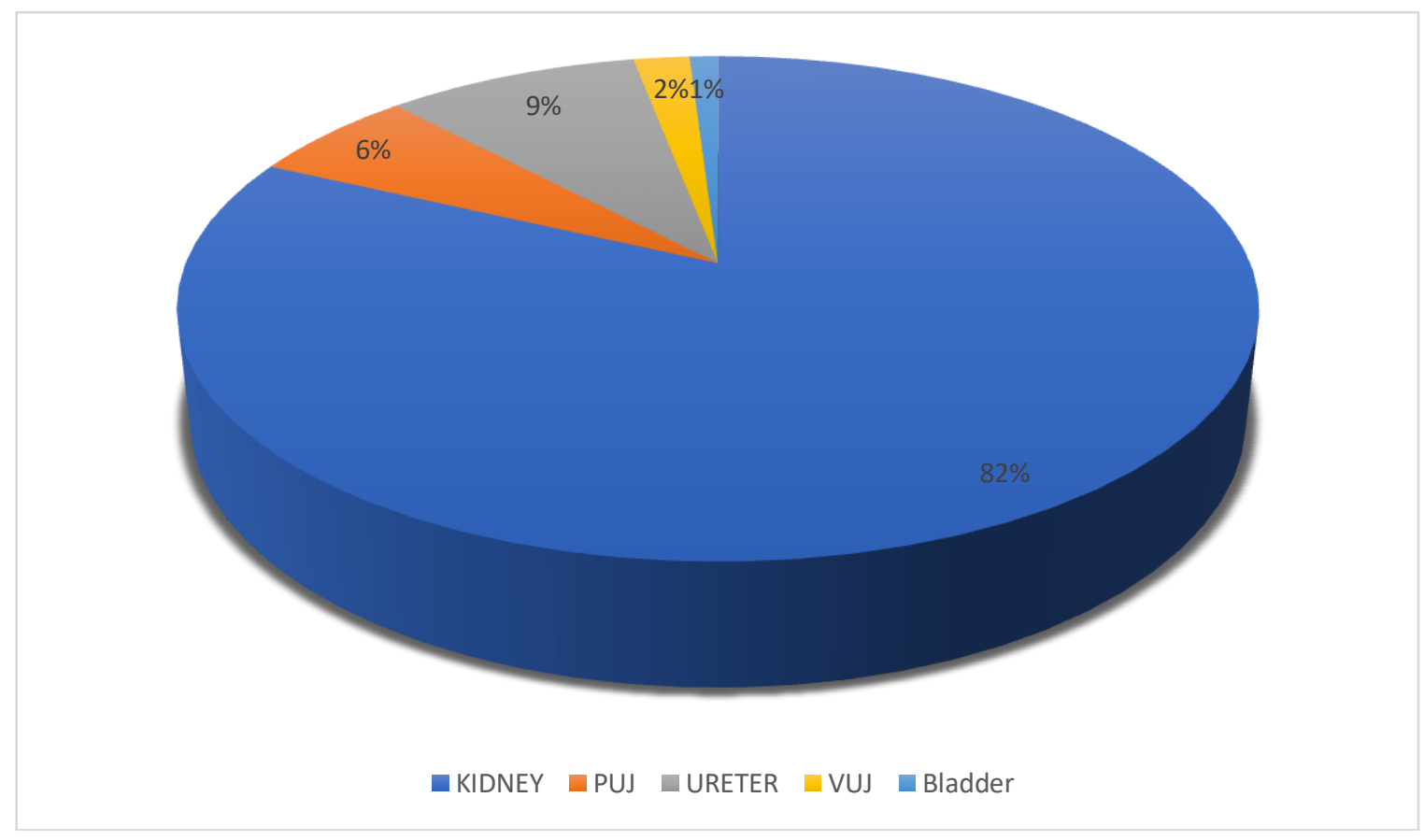

Figure 2: Anatomical location of calculi irrespective of age group and sex

The anatomical location of the urinary calculi showed no variation according to age group and sex of the patients. In males $53.3 \%$ of stones were located in the kidney and $5.1 \%$ in the ureter. In the females $28.4 \%$ were located in the kidney and 3.7 in the ureter. All the age groups had the highest number of calculi occurring in the kidney. The anatomical locations of the stones according to sex is as shown in figure 3 whereas Table 3 shows the anatomical locations according to age groups. 


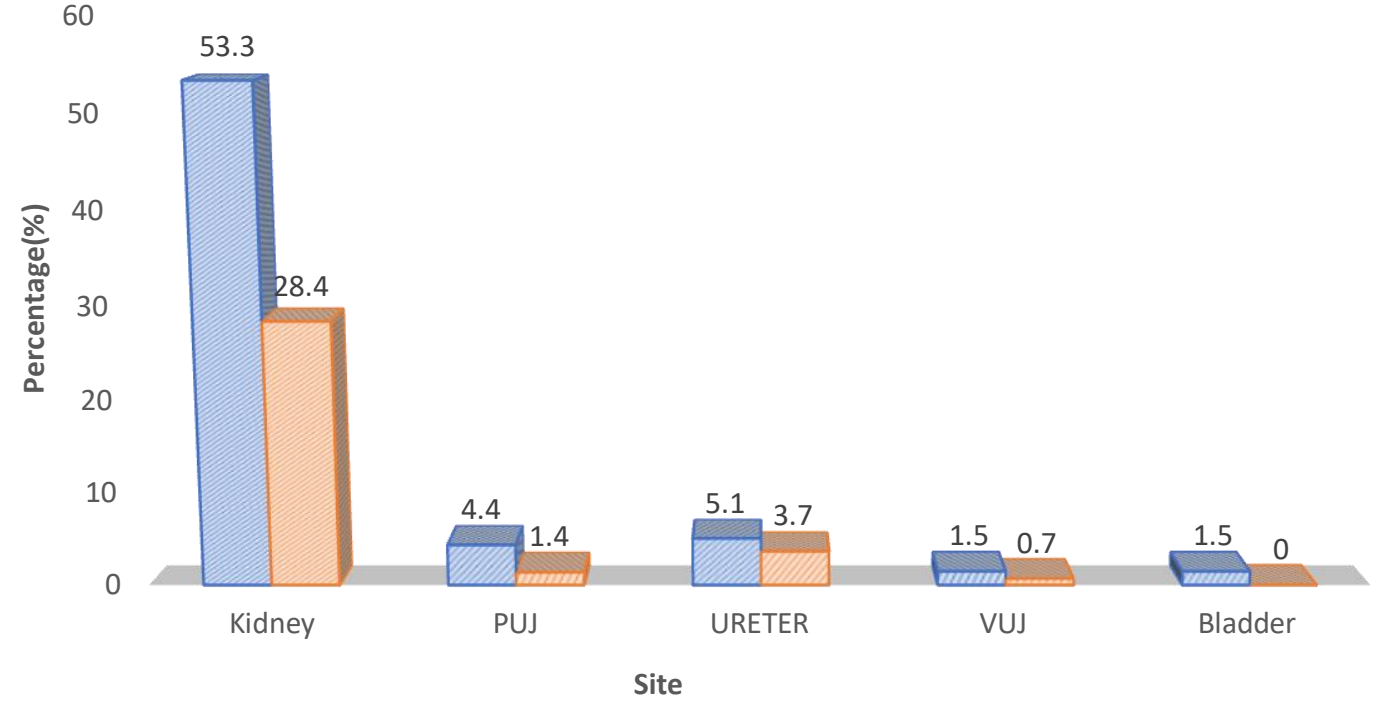

Figure 3: Calculi anatomical location according to age group and side.

Table 3: Calculi anatomical location according to age group and side.

\begin{tabular}{|l|l|l|l|l|l|l|l|l|l|l|}
\hline $\begin{array}{l}\text { Age } \\
\text { group } \\
\text { (yrs) }\end{array}$ & \multicolumn{9}{|l|}{ Anatomical location and side } \\
\hline & Kidney & \multicolumn{2}{|l|}{ PUJ } & Ureter & VUJ & Bladder & \\
\hline & Number(\%) & Number(\%) & \multicolumn{2}{l|}{ Number(\%) } & Number(\%) & Notal (\%) \\
\hline & Rt & Lt & Rt & Lt & Rt & Lt & Rt & Lt & & \\
\hline $21-30$ & $3(2.2)$ & $4(2.9)$ & $1(0.7)$ & $1(0.7)$ & & $1(0.7)$ & & & & $10(7.2)$ \\
\hline $31-40$ & $12(8.8)$ & $28(20.4)$ & $3(2.2)$ & $1(0.7)$ & $6(4.5)$ & & & & & $50(36.6)$ \\
\hline $41-50$ & $8(5.9)$ & $19(13.9)$ & & $2(1.5)$ & $1(0.7)$ & $2(1.5)$ & $1(0.7)$ & $2(1.5)$ & & $35(25.7)$ \\
\hline $51-60$ & $4(2.9)$ & $4(2.9)$ & & $1(0.7)$ & $1(0.7)$ & & & & & $10(7.2)$ \\
\hline $61-70$ & $13(9.5)$ & $13(9.5)$ & & & & & & & $1(0.7)$ & $27(19.7)$ \\
\hline $71-80$ & $2(1.5)$ & $1(0.7)$ & & & & & & & & $3(2.2)$ \\
\hline $81-90$ & $1(0.7)$ & & & & & $1(0.7)$ & & & & $2(1.4)$ \\
\hline Total & $43(31.5)$ & $69(50.3)$ & $4(2.9)$ & $5(3.6)$ & $8(5.9)$ & $4(2.9)$ & $1(0.7)$ & $2(1.5)$ & $1(0.7)$ & $137(100)$ \\
\hline
\end{tabular}

Of the 112 renal calculi 23 stones were found in the right kidney (17 in males and 6 in females) and 36 were found in the left kidney (26 in males and 10 in females). 53 stones were found in both kidneys of some of the patients (21 in males and 32 in females). There were more stones on the left kidney than the right kidney (Table 4).

Table 4: Side distribution of stone by gender.

\begin{tabular}{|l|l|l|l|}
\hline Side & \multicolumn{2}{|c|}{ Gender } & Total \\
\hline & Male & Female & \\
\hline KIDNEY & & & \\
\hline
\end{tabular}




\begin{tabular}{|l|l|l|l|}
\hline Right & $17(26.6)$ & $6(12.5)$ & $23(20.5)$ \\
\hline Left & $26(40.6)$ & $10(20.8)$ & $36(32.2)$ \\
\hline Both & $21(32.8)$ & $32(66.7)$ & $53(47.3)$ \\
\hline Total & $64(100.0)$ & $48(100.0)$ & $112(100.0)$ \\
\hline PUJ & & & \\
\hline Right & $3(50.0)$ & $1(50.0)$ & $4(50.0)$ \\
\hline Left & $3(50.0)$ & $1(50.0)$ & $4(50.0)$ \\
\hline Total & $6(100.0)$ & $2(100.0)$ & $8(100.0)$ \\
\hline URETER & & & \\
\hline Right & $3(42.9)$ & $5(100.0)$ & $8(66.7)$ \\
\hline Left & $4(57.1)$ & $0(0.0)$ & $4(33.3)$ \\
\hline Total & $7(100.0)$ & $5(100.0)$ & $12(100.0)$ \\
\hline VUJ & & & \\
\hline Right & $0(0.0)$ & $0(0.0)$ & $0(0.0)$ \\
\hline Left & $0(0.0)$ & $1(50.0)$ & $1(33.3)$ \\
\hline Both & $1(100.0)$ & $1(50.0)$ & $2(66.7)$ \\
\hline Total & $1(100.0)$ & $2(100.0)$ & $3(100.0)$ \\
\hline
\end{tabular}

In both males and females, most stones were located in the middle pole followed by lower pole, upper pole (Figure 4).

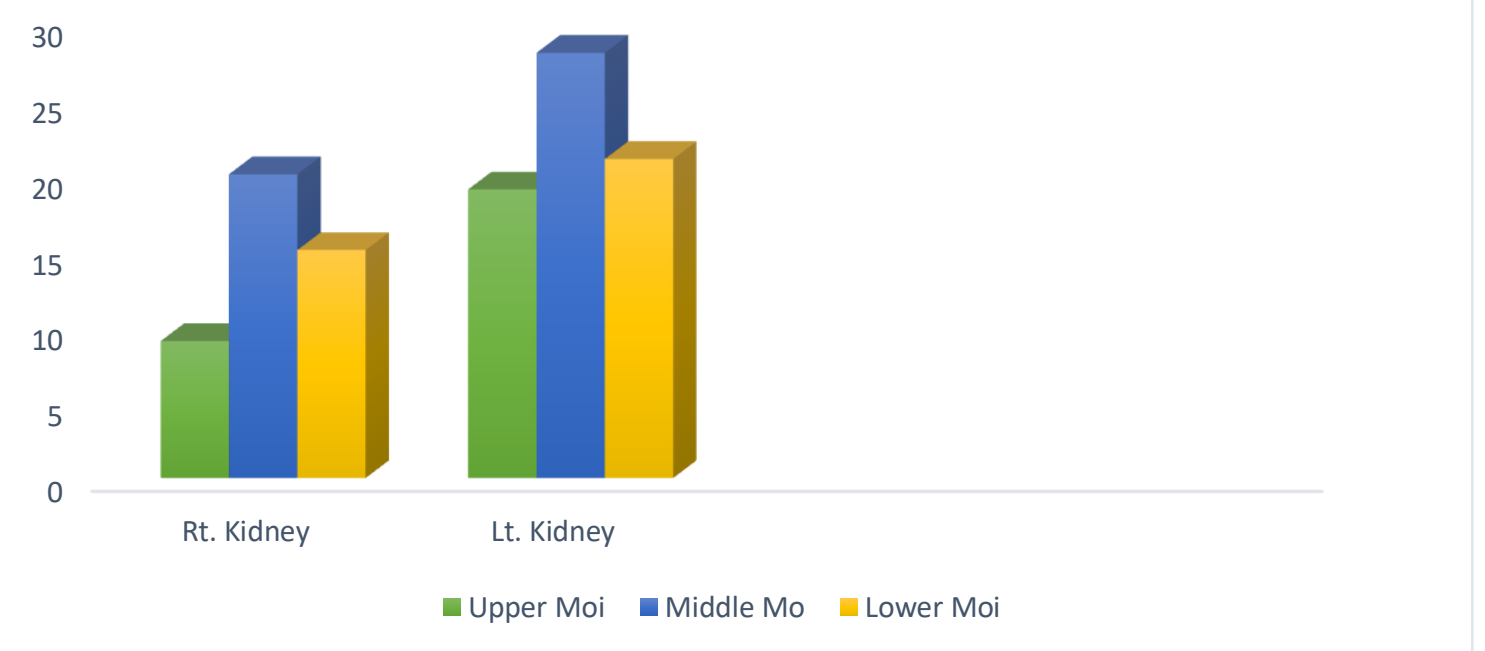

Figure 4: Distribution of stones in the poles (moieties) of the kidneys

Figure 5 shows the distribution of calculi in the ureter. $12(8.8 \%)$ stones were ureteric stone. Most stones were present in the lower ureter 6(50.0\%) followed by upper 4(33.3\%) and middle ureter 2(16.7\%) for the two ureters combine. Analysis of the number of stones in the right ureter show 3 stones in the upper and lower ureter with 2 stones in the middle part of the ureter. Whereas on the left ureter, 3 stones were noted in the lower ureter, 1 calculus in the upper ureter. No stone was located in the middle ureter on the left. 


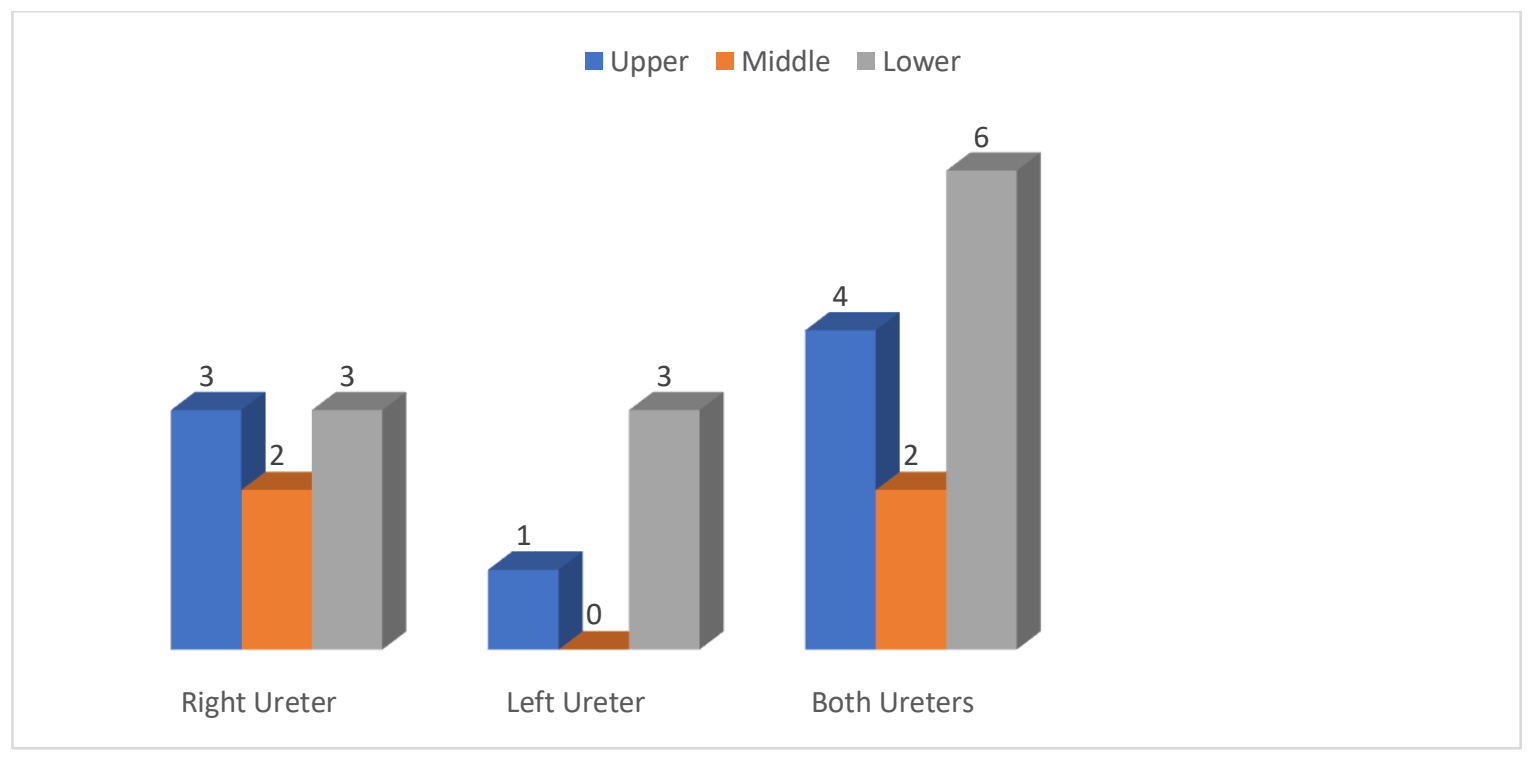

Figure 5: Distribution of calculi within the ureters according to side.

There were 10 patients with calculi in multiple locations (Figure 6). 5 patients ( 2 males and 3 females) had stones in two locations (the kidney and ureter), 3 patients ( 2 males and 1 female) had stones in two locations (the kidney and PUJ), 1 male patient had calculi located in the kidney and bladder while a male patient had calculi in three locations (kidney, PUJ and ureter)

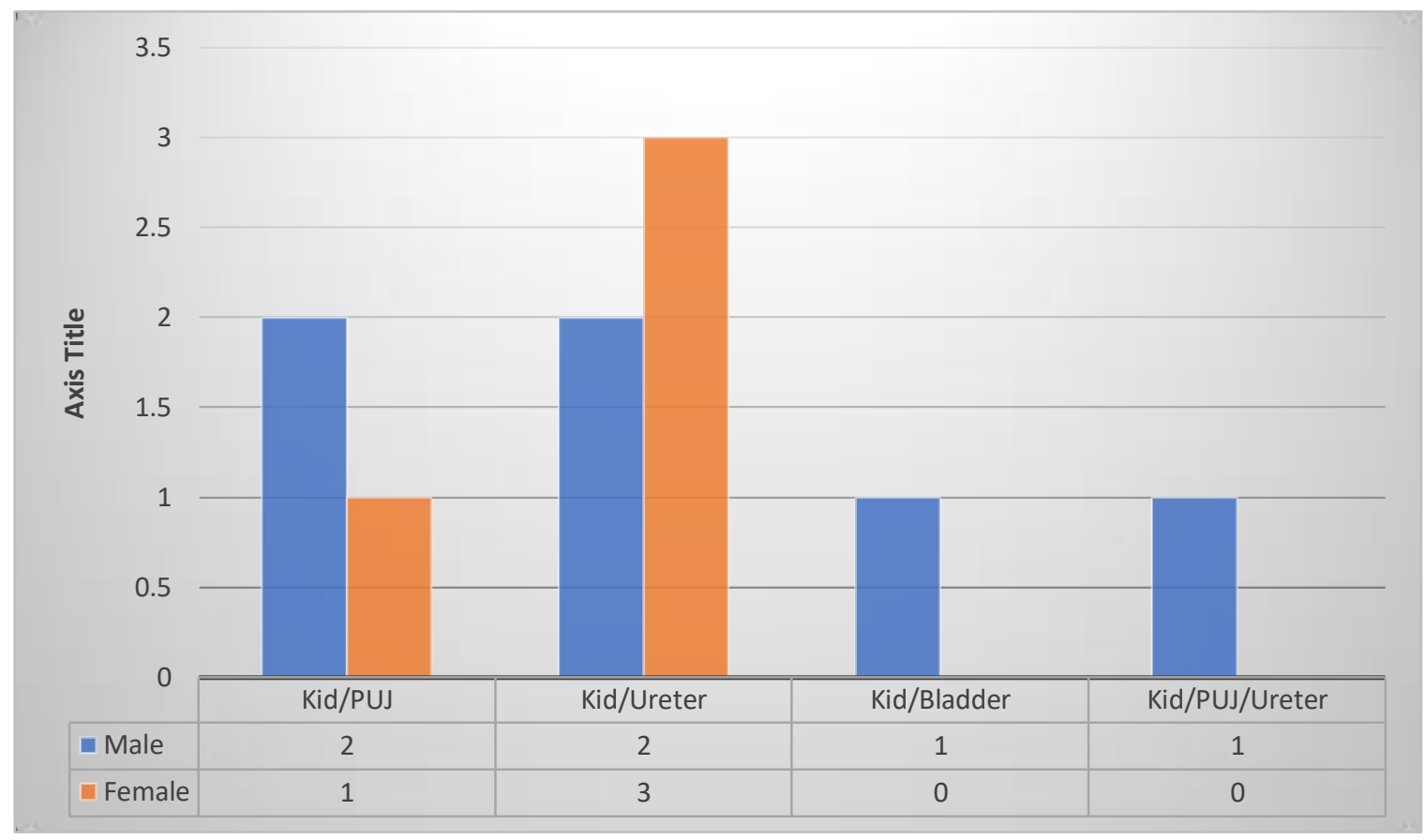

Figure 6: Distribution of calculi in multiple locations by patients gender.

\section{Discussion}

Urolithiasis is quite a common problem in developing countries like Nigeria as it is elsewhere in the developed countries. Our study showed that males are more affected than females with a male to female ratio of 2.13:1. This is corroborated by studies that documented a male to female ratio of 3.25:1 in Enugu ${ }^{11}$, 4:1 recorded by Monu $^{12}$ in Benin, Nigeria. Elsewhere in Maiduguri, Northern Nigeria and Nepal, Mshelia et 
$a l^{13}$ and Chand $e t a l^{8}$ also reported the predominance of calculi in men with a male to female ratio of 12:1 and $1.35: 1$ respectively.

This study shows that people of age group 31-40 years have the highest percentage of calculus which is similar to the 31-40 year age group recorded by Mbonu et $a^{14}, 30-39$ age group recorded in Saudi Arabia ${ }^{15}$ and 30-49 year age group reported in Enugu ${ }^{11}$. A younger age group 20-29 is reported in Nepal ${ }^{8}$. The reason for the male predominance and high incidence of urinary stone in this age group is not known, but several researchers have different observations which may relate to diet, hypercalciuria, hyperparathyroidism, hypocitruria as well as large muscle mass of men when compared to that of women ${ }^{8,16}$. A study has found that men have mean higher oxalate concentrations than women ${ }^{17}$.

Renal calculi has the highest frequency in both sexes followed by the ureter with the least stones found in the bladder. This is consistent with findings of Mshelia et $a l^{13}$ and Wathigo et $a l^{18}$ which also recorded highest frequency of stones in the upper urinary tract. In contrast to our finding, studies carried out in Nigeria $^{14}$, Nepal ${ }^{8}$ and Saudi Arabia ${ }^{15}$ reported the urinary bladder with the highest frequency of stone in the urinary tract. We also found more stones in the left kidney than the right kidney and in both sexes, more calculi are located in the middle pole followed by the lower and the upper pole of the kidneys bilaterally. This differs from the study by Chand $e t a l^{8}$ who reported the location of stones to be more in the lower pole followed by the middle and the upper poles of the kidneys in both gender. The reason for the stone distribution in the different poles of the kidney cannot be explained.

In the ureter, stone distribution were more in the lower followed by the upper and the middle parts of the ureter respectively. This is corroborates the findings of study done in $\mathrm{Nepal}^{8}$ which also recorded the highest frequency of ureteric stone in the lower followed by the upper and middle parts of the ureter.

\section{Conclusion}

Urolithiasis is a common problem in developing countries like Nigeria with the reproductive aged males predominantly affected than females. The calculi are commonly located in the kidney, ureter, PUJ, VUJ and the urinary bladder in descending order respectively. Most kidneys stones are located in the middle moiety of the kidney. Distal ureter is the most common site of ureteric stone. Computed Tomography is vital in locating urinary calculi for ease of accessibility for treatment.

\section{References}

[1] Chung, Melissa J. Urolithiasis and Nephrolithiasis. Journal of the American Academy of Physician Assistants:September 2017; vol. 30-Issue9: p 49-50. doi: 10.1097/01.JAA.0000522145.aa. Accessed on $16 / 3 / 2018$.

[2] Ansari MS, Gupta NP. Impact of socioeconomic status and management of urinary stone disease. Urol Int'l 2003; 70: 255-61.

[3] Curhan GC. Epidemiology of stone disease. Urol Clin North Am 2007;34(3):287-293.

[4] Pak CY. Kidney stones. Lancet 1998;351(9118): 1797-1801.

[5] Soucie JM, Thun MJ, Coates RJ, McClellan W, Austin H. Demographic and geographic variability of kidney stones in the United States. Kidney Int 1994;46(3):893-899.

[6] Mungadi IA, Ntia IO, Wek Opara, Sani AA. Urolithiasis in Sokoto, North Western Nigeria. Sahel Medical Journal 2006; 9(1): 10-14.

[7] Ekwere PD. Urinary calculous disease in South Eastern Nigeria. Afri J Med Sci 1995; 24(3): 289-95.

[8] Chand RB, Shah AK, Pant DK Paudel S. Common site of urinary calculi in kidney, ureter and bladder region. Nepal Med Coll J. 2013; 15(1): 5-7.

[9] Cao D, Yang L, Liu L, Yuan H, Qian S, Lv X, et al. A comparison of nifedipine and tamsulosin as medical expulsive therapy for the management of lower ureteral stones without ESWL. Sci Rep 2014;4:5254.Odoemene CA, Okere P, Ugonabo MC. Ureterolithiasis: Management in an environment with limited facilities. Niger J Clin Pract 2017;20:622-8.

[10] Turk C KT, Petrik A, Sarica K, et al. Guidelines on urolithiasis 2014. http://uroweb.org/wpcontent/uploads/22-Urolithiasis_LR.pdf. Accessed on $28^{\text {th }}$ July, 2019.

[11] Meka IA, Ugonabo MC, Ebede SO, Agbo EO. Composition of uroliths in a tertiary hospital in South East Nigeria. Afri Health Sci.2018;18(2): 437-445. https://dx.doi.org/10.4314/ahs.v18i2.29

[12] Monu JU. Pattern of urolithiasis in Benin City, Nigeria. J Natl Med Assoc 1989; 81(6): 695-698. 
[13] Mshelia DS, Gali DM, Naaya UH, Habu SA. Chemical composition of urinary calculi in Maiduguri, Nigeria. African J Med and Med Sci 2005; 34: 185-188.

[14] Mbonu O, Attah C, Ikeakor I. Urolithiasis in an African population. Int Urol Nephrol. 1984; 16:291296.

[15] Jarrar BM, AL-Enazi MM, Al-Messar S. Chemical composition of urinary calculi from Al-jouf province of Saudi Arabia. JRMS. 2007; 14(3): 15-19.

[16] Durgawale P, Sharrif A, Hendri A, Patil S, Sontakke A. Chemical analysis of stones and its significance inurolithiasis. Biomedical Research. 2010;21(3): 305-310.

[17] Curhan GC. Epidemiologic evidence for the role of oxalate in idiopathic nephrolithiasis. J Endourol 1999 Nov;13(9):629-31.

[18] Wathigo FK, Hayombe A, Maina D. Urolithiasis analysis in a multiethnic population at a tertiary hospital in Nairobi, Kenya. BMC Res Notes. 2017;10(1):158. 